\title{
Learning Strategies of Successful and Unsuccessful University Students
}

\author{
Ali Simsek \\ Jale Balaban \\ Anadolu University, Turkey
}

\begin{abstract}
The purpose of this study was to assess the most commonly used learning strategies of undergraduate students and how these strategies were related to their academic performance. Toward this purpose, a 60 item Likert scale was administered to a sample of 278 undergraduate students. The students were selected based on their cumulative grand-point-average as the most successful and the least successful five senior-year students from each majoring area in the faculties of arts, engineering, science, communication, and sports. The Cronbach's Alpha reliability coefficient of the scale was 0,93 . Results showed that successful students used more, varied, and better learning strategies than unsuccessful students. Female students were more effective in selecting and using appropriate strategies than male students. There were a variety of differences among fields of study; students of fine arts used the strategies least, while students of sports used them the most. The most preferred group of strategies was metacognitive strategies, whereas the least preferred group was organization strategies. The same pattern was found for the level of success, gender, and field of study. The results overall imply that certain strategies contribute to student performance more than other strategies, and majority of university students are aware of this situation.
\end{abstract}

Keywords: Cognitive strategies; Higher education; Learning strategies; University students.

\section{Introduction}

Learning strategies have long been an important issue in the field of education. It is generally accepted that instructional practices should assess and accommodate learning strategies of individual students. It is, however, not an easy task to design and implement truly adaptive modes of instruction in public education because learning strategies may vary significantly from one student to another. Due to this nature, learning strategies have also been a critical issue for instructional designers because they are to develop instructional systems that are sensitive to learning strategies of each student, both in group instruction and individual learning contexts.

Instructional designers and classroom teachers are generally aware that there are a number of learning strategies that students can select and employ. However, it is not clear on what basis students select certain strategies and why they prefer them instead of others (Gu, 2005; Simsek, 2006). For example, can the field of study be a factor in selecting strategies or does gender affect the choice of strategy? It is also true that educators are curious about the relationship between the use of strategies and generating various learning outcomes such as 
achievement, perseverance, and attitudes. One may ask if there is a meaningful correlation between the use of certain strategies and academic performance or if the past achievement levels of students influence their choice of strategies. All these questions are critical and answers are worth to know for producing successful learning.

It is not surprising that students can use a wide variety of strategies in the learning process. Presumably, there may be as many strategies as the number of students. It is because each student selects and employs a different strategy depending upon instructional variables such as individual differences, types of domains, teaching methods, amount of time, learning technologies, kinds of feedback, required level of mastery, ways of measurement etc. Needless to say that these variables are also important from the point of designing effective, engaging, and efficient instruction (Milano \& Ullius, 1998).

The spectrum of learning strategies expands from simple repetition to internal motivation of learners. Categorically stating, Weinstein and Mayer (1986) classify them into five major groups. These groups include strategies of rehearsal, elaboration, organization, metacognition, and motivation. The first three categories of this classification also have sub-clusters of basic and complex activities. The present study merged these sub-clusters and employed the five major groups of strategies as described by Simsek (2006).

Rehearsal strategies cover activities for identifying and repeating important segments of the given material. Memorizing, loud-reading, listing concepts, highlighting, putting special marks, underlining, using mnemonics, and taking personal notes are some examples of the strategies in this category

Elaboration goes beyond the given content and extends it with additional information coming from the student. Using new words in a sentence, paraphrasing information, summarizing, matching, applying analogies, generating metaphors, making comparisons, writing questions, and forming mental images are some examples of elaboration strategies.

Organization includes activities of reviewing and restructuring the presented material. The student finds the existing structure of the content inappropriate and produces alternative structure. Outlining, creating tables, classifying, re-grouping, connecting pieces, generating concept maps, and listing differently are common strategies in this category.

Metacognition usually deals with self-awareness of a student about his/her own capability in a particular learning area. The student evaluates his/her performance and tries to come up with better ways of learning. Self-critique, taking responsibility, personal reflection, individual monitoring, and changing study habits are some examples of metacognitive strategies.

Motivational strategies contain the student's perceptions and conscious efforts to perform and feel better. Attention focusing, directing anxiety, effective time management, reducing stress, developing interest, encouraging internal motivation, and setting meaningful ideals are several examples of strategies in this category.

Theoretical basis of learning strategies (also called cognitive strategies) is very strong. It comes from the basic assumption that every person has his/her own individual differences including how he/she learns. In other words, every learner is unique so that he/she should be treated differently in educational practices. It goes without saying that instruction that ignores the uniqueness of individual learners has a very low chance of succeeding. 
There is considerable amount of research studying what types of instructional approaches can be employed to accommodate students' learning strategies, how they can be used with different groups of learners, which strategies are functional in various areas of learning, and what kinds of results have been obtained from actual practices.

The overall results of the studies are highly encouraging. In general, successful students employ more and better learning strategies than unsuccessful students (Cho \& Ahn, 2003; Paris \& Myers, 1981; Tait and Entwhistle, 1996). Learning strategies interact with personal characteristics of students. There is no ideal strategy which generates success in all learning situations. Students should be trained to develop an understanding and skills for using appropriate strategies that satisfy their needs (Weinstein, 1987). Constructivist learning approaches are usually more effective and engaging than behaviorist approaches to accommodate individual strategies of learners. Interactive technologies provide increased opportunities for the use of learning strategies generating better academic achievement and attitudes (Eshel \& Kohavi, 2003). Teaching strategies should be compatible with learning strategies for successful and satisfying results in educational practices (Garner, 1990).

There are also experimental studies examining the effects of particular strategies on learning. Wade and Trathen (1989) investigated the impact of highlighting ideas in a text on perceiving the importance of those ideas and learning them. They found that effective study requires more than underlining, emphasizing, and note-taking. Questions were useful for all students, particularly for low-ability learners.

Wittrock and Alessandrini (1990) investigated the influences of reading text, using analogies, and producing summaries on analytical and holistic capacities. Results showed that groups employing analogies and summaries outperformed those employing reading only strategy because those strategies stimulated higher level of analysis and synthesis. Hooper, Sales and Rysavy (1994) further found that writing summaries produced higher performance than using analogies for university students because the students were not really successful in producing good analogies.

Braten and Olaussen (1998) investigated the relationship between motivational beliefs and the use of learning strategies. They found that when students work hard toward accomplishing a goal, they employ more and better strategies. McWhaw and Abrami (2001) confirmed that students with high level of interest use more strategies than those with low level of interest in a learning area. This is consistent with the result that students have more power or control over the use of strategies than teachers (Eshel \& Kohavi, 2003).

Sizoo, Malhotra and Bearson (2003) compared learning strategies of students in distance education and traditional face-to-face education. They found no difference for male students in both modes of instruction. However, female students in distance education programs were more successful than their counterparts in traditional programs. The literature also suggests that online learners usually have higher motivation and use more advanced strategies than traditional classroom learners.

Within the context of the above results, this study examines whether high-achieving students and low-achieving students at the university use different learning strategies and to what extent their preferences are related to their performance. More specifically, empirical answers to the following questions were investigated: (a) Do students with high grade point average 
employ different strategies than students with low grade point average? (b) Is there a significant difference between strategy preferences of male and female students? (c) Do students in various fields of study use different strategies? (d) Is there a meaningful correlation between students' use of various strategies and their achievement?

\section{Methods}

\section{Subjects}

The sample of the study included 278 undergraduate students at Anadolu University in Turkey. All subjects were senior-year students. The students were selected according to their departments and cumulative grade point averages. Fields of study were determined as science (Faculty of Science), technical (Faculty of Engineering), social sciences (Faculty of Communication), arts (Faculty of Fine Arts), and sports (Faculty of Physical Education and Sports).

Distribution of departments according to faculties was as follows: (a) Science: Mathematics, physics, biology, chemistry, and statistics; (b) Engineering: Computer, environmental, civil, electronics, industrial, chemistry, material science, and architecture; (c) Communication: Journalism, Advertising, Communication, Television; (d) Arts: Animation, glass, printing, graphics, sculpture, internal design, drawing, and ceramics; (e) Sports: Coaching, physical education, recreations, and sports management.

High-achieving students were identified as those who were in the top-five of the departmental ranks, whereas low-achieving students were identified as those who were in the bottom-five of the departmental ranks. The distribution of subjects according to their gender, achievement level, and respective fields of study is presented in Table 1.

Table 1. Distribution of Subjects According to Independent Variables of the Study

\begin{tabular}{|c|c|c|c|c|c|c|c|c|c|c|}
\hline \multirow[t]{2}{*}{ Field of study } & \multicolumn{4}{|c|}{ High-Achieving } & \multicolumn{3}{|c|}{ Low-Achieving } & \multicolumn{3}{|c|}{ Total } \\
\hline & & Male & Female & Total & Male & Female & Total & Male & Female & Total \\
\hline \multirow[t]{2}{*}{ Science } & $\mathrm{n}:$ & 9 & 16 & 25 & 13 & 12 & 25 & 22 & 28 & 50 \\
\hline & $\%:$ & 03.2 & 05.8 & 09.0 & 04.7 & 04.3 & 09.0 & 07.9 & 10.1 & 18.0 \\
\hline \multirow[t]{2}{*}{ Technical } & $\mathrm{n}:$ & 21 & 19 & 40 & 33 & 7 & 40 & 54 & 26 & 80 \\
\hline & $\%:$ & 07.6 & 06.8 & 14.4 & 11.9 & 02.5 & 14.4 & 19.4 & 09.4 & 28.8 \\
\hline \multirow[t]{2}{*}{ Social Sciences } & $\mathrm{n}:$ & 7 & 13 & 20 & 15 & 5 & 20 & 22 & 18 & 40 \\
\hline & $\%:$ & 02.5 & 04.7 & 07.2 & 05.4 & 01.8 & 07.2 & 07.9 & 06.5 & 14.4 \\
\hline \multirow[t]{2}{*}{ Arts } & $\mathrm{n}:$ & 19 & 16 & 35 & 20 & 13 & 33 & 39 & 29 & 68 \\
\hline & $\%:$ & 06.8 & 05.8 & 12.6 & 07.1 & 04.7 & 11.8 & 14.0 & 10.4 & 24.4 \\
\hline \multirow[t]{2}{*}{ Sports } & $\mathrm{n}:$ & 11 & 9 & 20 & 14 & 6 & 20 & 25 & 15 & 40 \\
\hline & $\%:$ & 04.0 & 03.2 & 07.2 & 05.0 & 02.2 & 07.2 & 09.0 & 05.4 & 14.4 \\
\hline \multirow[t]{2}{*}{ TOTAL } & $\mathrm{n}:$ & 67 & 73 & 140 & 95 & 43 & 138 & 162 & 116 & 278 \\
\hline & \%: & 24.1 & 26.3 & 50.4 & 34.1 & 15.5 & 49.6 & 58.2 & 41.8 & 100.0 \\
\hline
\end{tabular}

The percentages of the high-achieving students and the low-achieving students were almost equal (50\%). The highest percentage of students appeared in the technical field $(29 \%)$, followed by arts (24\%) and science (18\%). The percentages of students in social sciences and sports were the same ( $14 \%$ each). This was the natural consequence of the number of 
departments in these fields at the university because ten students (five high-achieving and five low-achieving) were selected from each department. As far as gender is concerned, $58 \%$ of the subjects were male and $42 \%$ were female.

\section{Data Gathering}

The researchers reviewed the existing literature and data gathering instruments used in previous studies. They decided that it was more appropriate to develop a new instrument for the present study. Taking the classification of Weinstein and Mayer (1986), they designed a Likert-type scale to assess learning strategies of university students. An expert panel of three colleagues reviewed the draft of the scale. Considering their comments and suggestions, some minor revisions were made. Then, the scale was pilot-tested with a small group of 30 undergraduate students. Having assured the reliability and making a few changes, the scale was finalized.

The final version of the scale included a total of 60 five-point items distributed equally among five categories of learning strategies. The categories were rehearsal, elaboration, organization, metacognition, and motivation. Sample items for each category were as follows: "I repeat important points of the subject until I learn" (Rehearsal); "I produce analogies when I study" (Elaboration); "I break down the content when appropriate" (Organization); "I change my strategies if they don't work for me" (metacognition); and "I believe that success depends on my own efforts" (motivation).

After identifying the students who were going to participate in the study, the data gathering instrument was administered to each student individually and independently during a period of two weeks. Each student completed the scale and returned it to his or her department secretary. Upon the arrival of all completed data gathering instruments, the statistical analysis of data was performed. Based on the total scores, the Cronbach's Alpha reliability coefficient was calculated as 0,93 for the whole scale. The reliability coefficients for categories of the scale ranged from 0,72 (rehearsal) to 0,85 (metacognition).

\section{Data Analysis}

Statistical analysis of data was performed through SPSS in accordance with the research questions. Independent variables were the field of study, gender, and the overall level of academic performance of students. Dependent variables were students' total strategy scores and sub-scores according to categories of the scale. Considering the purpose and design of the study, correlation, ANOVA, and multiple regression tests were performed in addition to the measures of central tendency and variability. Unless otherwise indicated, the significance level was accepted as $\alpha=0,05$.

\section{Findings}

\section{Level of Achievement}

The means and standard deviations of high-achieving and low-achieving students according to their total strategy scores and category sub-scores are mentioned in Table 2 . It should be 
noted that the maximum possible score for the whole scale was 300 (60x5), and the maximum possible score for each sub-category was $60(12 \times 5)$.

Table 2. Means and Standard Deviations for Successful and Unsuccessful Students

\begin{tabular}{lccccrr}
\hline \hline Level & \multicolumn{5}{c}{ Strategies } \\
& Rehearsal & Elaboration & Organization & Metacognition & Motivation & Total \\
\hline \hline High $(n=140)$ & & & & & \\
M: & 44.87 & 43.12 & 38.53 & 47.15 & 44.54 & 218.21 \\
SD: & 6.63 & 7.44 & 9.34 & 7.80 & 7.37 & 3.97 \\
Low $(n=138)$ & & & & & & \\
M: & 42.13 & 39.50 & 36.71 & 41.59 & 78.23 & 198.41 \\
SD: & 6.21 & 6.80 & 8.16 & 7.14 & 7.15 & 3.25 \\
Total $(n=278)$ & & & & & & \\
M: & 43.63 & 41.32 & 37.63 & 44.39 & 41.41 & 208.39 \\
SD: & 6.53 & 7.35 & 8.80 & 7.97 & 7.91 & 30.93 \\
\hline \hline
\end{tabular}

High-achieving students $(M=218.21)$ used more strategies than low-achieving students $(M=198.41)$. The ANOVA results revealed a significant difference for the achievement levels of students $[F(1,274)=23,68 ; p<0,001]$, in favor of high-achievers. The same pattern between highachieving and low-achieving students was also observed for categories of the scale; the biggest difference between the two groups was found for motivation strategies $(d=6,31)$, while the smallest difference was found for organization strategies $(d=1,82)$. With exception of the difference for organization strategies $(p=0,85)$, all the differences for other categories were significant $(p<0,001)$.

\section{Gender}

The means and standard deviations of both total scores and category sub-scores according to gender of students are given in Table 3.

Table 3. Means and Standard Deviations for Male and Female Students

\begin{tabular}{lccccrr}
\hline \hline Gender & \multicolumn{5}{c}{ Strategies } \\
& Rehearsal & Elaboration & Organization & Metacognition & Motivation & Total \\
\hline \hline Male $(n=162)$ & & & & & \\
M: & 41.80 & 40.59 & 36.32 & 43.46 & 40.49 & 202.67 \\
SD: & 6.48 & 7.06 & 7.99 & 8.13 & 7.56 & 29.37 \\
Female $(n=116)$ & & & & & 42.69 & 216.37 \\
M: & 46.19 & 42.35 & 39.46 & 45.68 & 8.24 & 31.40 \\
SD: & 5.71 & 7.65 & 9.56 & 7.60 & & 208.39 \\
Total $(n=278)$ & & & & & 41.41 & 30.93 \\
M: & 43.63 & 41.32 & 37.63 & 44.39 & 7.91 & \\
SD: & 6.53 & 7.35 & 8.80 & 7.97 & & \\
\hline \hline
\end{tabular}

Female students $(M=216.37)$ employed more strategies than male students $(M=202.67)$. The ANOVA results yielded a significant difference for gender $[F(1,274)=7,448 ; p<0,007]$, in favor of female students. Further analyses suggested that the same pattern was observed for categories; the largest difference was for rehearsal $(d=4,39)$ and the lowest difference was for 
elaboration $(d=1,76)$. As far as gender is concerned, all the differences for categories were significant $(p<0,003)$, except the one for elaboration $(p=050)$.

\section{Fields of Study}

The means and standard deviations of total strategy scores and category sub-scores of students according to study fields are presented in Table 4.

Table 4. Means and Standard Deviations According to Fields of Study

\begin{tabular}{lcccccr}
\hline \hline Level & & \multicolumn{6}{c}{ Strategies } \\
& Rehearsal & Elaboration & Organization & Metacognition & Motivation & Total \\
\hline \hline Science $(n=50)$ & & & & & & \\
M: & 45.12 & 41.62 & 38.86 & 44.26 & 42.70 & 212.56 \\
SD: & 5.93 & 6.87 & 9.46 & 6.54 & 6.67 & 26.99 \\
Technical $(n=80)$ & & & & & & \\
M: & 43.50 & 40.65 & 37.81 & 45.69 & 41.55 & 209.20 \\
SD: & 5.33 & 6.89 & 7.90 & 7.31 & 7.23 & \\
27.02 & & & & & & \\
Social $(n=40)$ & & & & & & \\
M: & 42.88 & 40.98 & 37.73 & 43.45 & 39.85 & 204.88 \\
SD: & 6.06 & 7.35 & 8.59 & 8.31 & 8.98 & 33.47 \\
Arts $(n=68)$ & & & & & & \\
M: & 41.34 & 41.09 & 35.24 & 42.09 & 39.44 & 199.19 \\
SD: & 7.74 & 7.81 & 8.23 & 8.99 & 8.52 & 32.62 \\
Sports $(n=40)$ & & & & & & \\
M: & 46.73 & 43.05 & 39.68 & 46.80 & 44.43 & 220.68 \\
SD: & 6.27 & 8.05 & 10.25 & 7.87 & 7.51 & 33.38 \\
Total $(n=278)$ & & & & & & \\
M: & 43.63 & 41.32 & 37.63 & 44.39 & 41.41 & 208.39 \\
SD: & 6.53 & 7.35 & 8.80 & 7.97 & 7.91 & 30.93 \\
\hline \hline
\end{tabular}

The highest mean of strategy use was found for the field of sports $(M=220.68)$, followed by science, engineering, and communication; the lowest mean was found for arts ( $M=199.19)$. The ANOVA results revealed a significant difference for the variable of study field $[F(1,268)=4,062 ; p<0,003]$. The differences among mean scores of categories within the context of study fields showed interesting findings. The differences for the categories of rehearsal $(p<0,001)$, metacognition $(p<0,016)$, and motivation $(p<0,011)$ were significant; however, the differences for the remaining two categories of elaboration $(p=0,540)$ and organization $(p<0,083)$ were not significant.

\section{Correlations}

The correlation coefficients among total strategy scores and sub-scores on the five categories of the scale are mentioned in Table 5.

All the correlations between categories were positive and significant $(p<.01)$. The lowest correlation was between organization and motivation ( $r=.462)$, while the highest correlation was between metacognition and motivation $(r=.716)$. As far as the relationships between total 
scores and category scores were concerned, they all were high and relatively close to each other; the lowest correlation was found for rehearsal ( $r=.748)$, and the highest was found for metacognition ( $r=.854)$.

Table 5. Correlations Among Categories of the Scale

\begin{tabular}{lccccc}
\hline \hline Strategy & Elaboration & Organization & Metacognition & Motivation & Total \\
\hline \hline Rehearsal & & & & & \\
Elaboration & .490 & .515 & .551 & .514 & .748 \\
Organization & & .617 & .619 & .508 & .806 \\
Metacognition & & & .526 & .462 & .794 \\
Motivation & & & & .716 & .854 \\
\hline \hline
\end{tabular}

The correlation coefficient between academic performance (operationalized as cumulative grade point average) and the use of learning strategies (described as total strategy score) was also positive and significant $(r=.28 ; p<.001)$. It means that when the students employed more strategies, their achievement also increased.

\section{Conclusions and Recommendations}

This study examined the relationship between learning strategies and academic performance of university students. The sample of university students was selected because they were assumed to be relatively more capable of selecting and using appropriate learning strategies compared to elementary and secondary students. Within the university environment, senioryear students were thought to be more conscious and experienced in the use of various strategies.

In general, a positive and significant correlation was found between the use of learning strategies and the level of academic performance. The more the learning strategies used, the higher the student performance was. However, the students did not prefer or employ all strategies equally. This is similar with the results of Cho and Ahn (2003), indicating that when students employ more strategies, they are likely to be more successful. This result is also thought to be in line with the results of McWhaw and Abrami (2001), concluding that students with higher level interest tend to use more strategies.

High-achieving students used more learning strategies than low-achieving students, both in frequency and variety. This is consistent with the existing literature (Paris \& Myers, 1981; Tait \& Entwhistle, 1996). However, the students used metacognitive strategies with the highest preference and organization strategies with the lowest; frequencies of other strategies were between these two categories without differing much. It appears that the university students can judge appropriateness and functionality of learning strategies that they employ. However, they do not change the structure of the given materials. It may be that restructuring learning content may not produce expected results for a number of systemic reasons (Garner, 1990). Among them may be teaching strategies of faculty members, organization of course contents, simplicity of learning tasks, designs of textbooks, variety of activities, perceived roles of instructors and learners, types of exams, and interdisciplinary links among various subject matter areas. 
Female students employed more learning strategies than male students. Such a pattern was the same for all achievement levels and fields of study. This result is somewhat similar to the results of Sizoo, Malhotra and Bearson (2003), suggesting that female students in distance education programs benefitted more from the use varied learning strategies. It may be due to the fact that female students generally represented a higher percentage within high-achieving groups in all fields of study so they both used more strategies and therefore outperformed male students.

The level of strategy use differed according to the fields of study. Students in the field of sports used more strategies than other groups. The difference between the students in sports and arts was particularly visible. Many may think that it was because they probably relied heavily on rehearsal strategies than any other category; however, this was not the case. Consistent with the general trend, the students in sports used metacognitive strategies most and organization strategies least. This may be due to two reasons. First, commonly used teaching methods and assessment tools might have played a significant role. For example, the area of sports requires daily practice, frequent testing, independent work, and personal evaluations; while the area of arts requires creative design, team projects, exhibitions, and portfolio evaluations. Secondly, as mentioned by Hooper, Sales, and Rysavy (1994), university students generally are not successful in certain strategies such as generating analogies, forming mental images, and changing the structure of the material. It appears that even the most experienced students should be trained about effective use of learning strategies.

Relationships between categories of the scale and their contributions to total strategy scores were high and significant. The best predictor of the total strategy score was metacognition and the lowest was rehearsal. However, the differences between the highest and the lowest predictor was within the range of $10 \%$, suggesting that it was not really significant and all the categories served as good predictors of the total strategy score. It is also true that categories were overlapping into each other. Stated differently, the categories of the scale were not totally independent from each other so that there was consistency in students' uses of various strategies (Weinstein \& Mayer, 1986). This provides evidence for the long-stated point that "there is no best strategy for all conditions of learning." In other words, using a learning strategy itself is a highly strategic decision because each strategy works differently under each instructional condition (Simsek, 2006).

Considering the results of the present study, further research is needed in several areas. First, preferred strategies of elementary and secondary students should be studied based on the fact that those students are not as capable as university students in deciding and employing proper learning strategies. Secondly, the effects of various strategies on learning of different types of contents should be examined under experimental conditions; such studies may reveal interactions between strategies and types of contents. Third, new studies should focus on why and to what extent successful students use different strategies than unsuccessful students. Fourth, possible links between students' use of preferred strategies and basic elements of an educational system should be explored. Fifth, future research should examine what really happens if all students go through strategy training as early as possible in their educational experiences. Finally, more experimental research is needed on the role of learning strategies on both cognitive and affective outcomes in technology-based learning environments. The results of the recommended studies may have great influences and serious implications both for educational researchers and practitioners. 


\section{References}

Braten, I. \& Olaussen, B. S. (1998). The relationship between motivational beliefs and learning strategy use among Norwegian college students. Contemporary Educational Psychology, 23, 182-194.

Cho, S. \& Ahn, D. (2003). Strategy acquisition and maintenance of gifted and non-gifted young children. Council for Exceptional Children, 69(4), 497-505.

Eshel, Y. \& Kohavi, R. (2003). Perceived classroom control, self-regulated learning strategies, and academic achievement. Educational Psychology, 23(3), 249-260.

Garner, R. (1990). When children and adults do not use learning strategies: Toward a theory and settings. Review of Educational Research, 60(4), 517-529.

Gu, P. Y. (2005). Learning strategies: Prototypical core and dimensions of variation (Working paper No: 10). Nanyang Technological University National Institute of Education Centre for Research in Pedagogy and Practice. China.

Hooper, S., Sales, G., Rysavy, S. D. (1994). Generating summaries and analogies alone and in pairs. Contemporary Educational Psychology, 19(1), 53-62.

McWhaw, K. \& Abrami, P. C. (2991). Student goal orientation and interest: Effects on students' use of self-regulated learning strategies. Contemporary Educational Psychology, 26, 311329.

Milano, M. \& Ullius, D. (1998). Designing powerful training: The sequential-iterative model. San Francisco, CA: Josey-Bass/Pfeiffer.

Paris, S. B. \& Myers, M. (1981). Comprehension monitoring, memory, and study strategies of good and poor readers. Journal of Reading Behavior, 13(1), 5-22.

Simsek, A. (2006). Bilissel stratejilerin ogretimi [Teaching cognitive strategies]. In A. Simsek (Ed.), Icerik turlerine dayali ogretim (pp.181-208). Ankara: Nobel.

Sizoo, S., Molhatro, N. K, \& Bearson, J. M. (2003). Preparing students for a distance learning environment: A comparison of learning strategies of in-class and distance learners. Educational Technology Systems, 31(3), 261-273.

Tait, H. \& Entwistle, N. J. (1996). Identifying students at risk through ineffective study strategies. Higher Education, 31, 97-116.

Wade, S. E. \& Trathen, W. (1989). Effects of self-selected study methods on learning. Journal of Educational Psychology, 81(1), 40-47.

Weistein, C. E. (1987). Fostering learning autonomy through the use of learning strategies. Journal of Reading, 30(7), 590-595.

Weinstein, C. E. \& Mayer, R. (1986). The teaching of learning strategies. In M. C. Wittrock (Ed.), Handbook of research on teaching (pp.315-327). New York: Macmillan.

Wittrock, M. C. \& Alessandrini, K. (1990). Generation of summaries and analogies and analytic and holistic abilities. American Educational Research Journal, 27(3), 489-502.

Correspondence: Ali Simsek, Professor, Faculty of Communication Sciences, Anadolu University, Yunus Emre Campus, Eskisehir, 26470, Turkey. 